\title{
Magneto-Hydrodynamics (MHD) Bioconvection Nanofluid Slip Flow over a Stretching Sheet with Microorganism Concentration and Bioconvection Péclet Number Effects
}

\author{
Falana Ayodeji ${ }^{1,}$, Alegbeleye Tope ${ }^{1}$, Owoeye Samuel ${ }^{2}$ \\ ${ }^{1}$ Department of Mechanical Engineering, University of Ibadan, Ibadan, Nigeria \\ ${ }^{2}$ Department of Mechanical Engineering, Federal University of Agriculture, Abeokuta, Nigeria
}

Email address:

falanaayode@gmail.com (F. Ayodeji)

*Corresponding author

To cite this article:

Falana Ayodeji, Alegbeleye Tope, Owoeye Samuel. Magneto-Hydrodynamics (MHD) Bioconvection Nanofluid Slip Flow over a Stretching Sheet with Microorganism Concentration and Bioconvection Péclet Number Effects. American Journal of Mechanical and Industrial Engineering. Vol. 4, No. 6, 2019, pp. 86-95. doi: 10.11648/j.ajmie.20190406.11

Received: June 2, 2019; Accepted: July 12, 2019; Published: January 4, 2020

\begin{abstract}
This study analyzes the effect of slip parameter, microorganism concentration and bioconvection Péclet number on Magneto-hydrodynamics (MHD) bioconvection nanofluid flow over a stretching sheet. Similarity transformation is employed to convert the governing partial differential equations into coupled non-linear ordinary differential equations with appropriate boundary conditions. These equations are solved numerically using fourth order Runge Kutta-Fehlberg integration method along with a shooting technique. The dimensionless velocity, temperature, nanoparticle concentration and density of motile microorganisms were obtained together with the local skin friction, reduced Nusselt, Sherwood and motile microorganism density numbers. It was observed that nanoparticle concentration decreases with increase in the nanoparticle concentration slip but increases as magnetic field parameter increases. Also the velocity of the fluid decreases with increase in both velocity slip parameter $\xi$ and magnetic field parameter M. It is also noticed that the temperature of the flow is continuously decreasing as the value of velocity slip parameter $\xi$, temperature slip parameter $\beta$ and concentration slip parameter $\gamma$ increase. Furthermore, as velocity and nanoparticle concentration slip parameters increase, the Nusselt number was observed to increase while the Sherwood number decreases. The skin friction coefficient also decreases as the values of velocity slip parameter increases. Finally we found that local microorganism transfer rate increases with greater values of bioconvection Lewis number Lb, microorganism concentration $\Omega$ and bioconvection Péclet number Pe. Comparisons between the previously published works and the present results reveal excellent agreement.
\end{abstract}

Keywords: Bioconvention Péclet, Slip Conditions, Nanofluid, MHD Flow and Heat Transfer

\section{Introduction}

Thermal conductivity plays a significant role in enhancing heat transfer. Fluids with small thermal conductivity such as oil, water and ethylene glycol are categorized as the poor heat transfer materials. There are several innovative techniques proposed for the heat transfer enhancement of fluids. One of such techniques is nanofluids. The term nanofluidswas coined by Choi [1] at the ASME Winter Annual Meeting, which refers to a liquid containing a dispersion of submicronic solid particles (nanoparticles) with typical length on the order of 1-50 nm. Nanofluids are used to enhance the thermal conductivity of base fluids. They have several engineering and applications in cooling and process industries. Buongiorno and $\mathrm{Hu}$ [2] and Buongiorno [3] presented a study of convective transport in nanofluids. Also, Daungthongsuk and Wongwises [4] investigated the effects of thermophysical properties of nanofluids on the convective heat transfer. Kuznetsov and Nield [5] employed the Brinkman and Darcy models to study the onset of convection in a horizontal layer of a porous medium filled with a nanofluid. They also obtained similarity solution of natural convective boundary-layer flow of a nanofluid past a vertical plate. Rana and Bhargava [6] studied the steady boundary- 
layer flow and heat transfer for different types of nanofluids near a vertical plate with heat generation effects. Makinde and Aziz [7] reported the similarity solutions for the thermal boundary layer of a nanofluid past a stretching sheet with a convective boundary condition. Bioconvection is a phenomenon that occurs when microorganisms swim upward microorganisms like algae tend to concentrate in the upper portion of the fluid layer thus causing a top heavy density stratification that often becomes unstable. Kuznetsov [8] studied both non-oscillatory and oscillatory nanofluid biothermal convection in a horizontal layer of finite depth and analyzed the dependence of the thermal Rayleigh number on the nanoparticle Rayleigh number and the bioconvection Rayleigh number. Khan and Makinde [9] investigated MHD flow of nanofluids with heat and mass transfer along a vertical stretching sheet in the presence of motile gyrotactic microorganisms. Xuand Pop [10] obtained a more physically realistic result using a passively controlled nanofluid model by an analysis of bioconvection flow of nanofluids in a horizontal channel. In a recent paper, Khan et al. [11] investigated the effects of both Navier slip and magnetic field on boundary-layer flow of nanofluids containing gyrotactic microorganisms over a vertical plate. Their results show that the bioconvection parameters tend to reduce the local concentration of motile microorganisms.

In this study, our main objective is to report the effect of concentration $\Omega$ and bioconvection Péclet number Pe on the rate of heat and mass transfer of a nanofluid over a stretching the bioconvection Lewis number Lb, microorganism

sheet with temperature and velocity slip, in which combined effects of magnetic field, nanoparticle, microorganism and thermal radiation are also considered.

\section{Mathematical Formulation}

Consider a two-dimensional steady state boundary layer flow of a nanofluid over stretching sheet with surface temperature $\mathrm{T}_{\mathrm{w}}$ and concentration $\mathrm{C}_{\mathrm{w}}$. The stretching velocity of the sheet is $\mathrm{u}_{\mathrm{w}}=\mathrm{ax}$, with a being a constant. Let the wall mass transfer be $V_{w}$, which will be determined later. The flow is assumed to be generated by stretching sheet issuing from a thin slit at the origin. The sheet is then stretched in such a way that the speed at any point on the sheet becomes proportional to the distance from the origin. The ambient temperature and concentration are $\mathrm{T}_{\infty}$ and $\mathrm{C}_{\infty}$ respectively. The flow is subjected to the combined effects of thermal radiation $R$ and a transverse magnetic field of strength $B_{0}$, which is assumed to be applied in the positive y direction

It is assumed that the induced magnetic field, the external electric field and the electric field due to the polarization of charges are negligible. Using scale analysis and following Buongiorno [12] and Kuznetsov [13], the governing equations can be written as

$$
\begin{array}{r}
\frac{\partial u}{\partial x}+\frac{\partial v}{\partial y}=0 \\
\mathrm{u} \frac{\partial u}{\partial x}+\mathrm{v} \frac{\partial u}{\partial y}=v \frac{\partial^{2} u}{\partial y^{2}}-\frac{\sigma B_{o}^{2} u}{\rho}
\end{array}
$$

In the above expressions $\mathrm{u}$ and $\mathrm{v}$ are the nanofluid velocity components, $\mathrm{T}$ is the temperature, $\mathrm{n}$ is the density of motile microorganisms, $\mathrm{p} \rho, \alpha, \mathrm{B}_{0}, \mathrm{D}_{\mathrm{b}}, \mathrm{D}_{\mathrm{t}}$ and $\mathrm{D}_{\mathrm{n}}$ are the fluid pressure, the density of the base fluid, electrical conductivity, magnetic field, the Brownian diffusion, thermophoresis diffusion coefficient and the diffusivity of microorganisms respectively.

The given boundary conditions are

$$
\begin{gathered}
\text { At } y=0, u=u_{w}+L \frac{\partial u}{\partial y}, v=V_{m}, T=T_{w}+\delta \frac{\partial T}{\partial y}, C=C_{w}+\varepsilon \frac{\partial C}{\partial y} \text { and } n=n_{w}+\zeta \frac{\partial n}{\partial y} \\
n \rightarrow n_{\infty} \text { as } \mathrm{y} \rightarrow \infty \mathrm{u} \rightarrow U_{\infty}=0, \mathrm{~T} \rightarrow T_{\infty}, \mathrm{C} \rightarrow C_{\infty}, n \rightarrow n_{\infty} \text { as } \mathrm{y} \rightarrow \infty
\end{gathered}
$$

Where $\mathrm{u}_{\mathrm{w}}=a x, \mathrm{~T}_{\mathrm{w}}=T_{\infty}+g\left(\frac{x}{l}\right)^{2}$,

$$
\mathrm{C}_{\mathrm{w}}=C_{\infty}+C\left(\frac{x}{l}\right)^{2}, \mathrm{n}_{\mathrm{w}}=n_{\infty}+D\left(\frac{x}{l}\right)^{2}
$$

$$
\begin{gathered}
\eta=y \sqrt{\frac{a}{v}} \\
\psi=\sqrt{\mathrm{a} v} x f(\eta) \\
\mathrm{u}=\frac{\partial \psi}{\partial y}, \mathrm{v}=-\frac{\partial \psi}{\partial x}, \mathrm{u}=\mathrm{a} x f^{\prime}(\eta), \mathrm{v}=-\sqrt{\mathrm{a} v} f(\eta) \\
\theta(\eta)=\frac{T-T_{\infty}}{T_{w-T_{\infty}}} \\
\phi(\eta)=\frac{C-C_{\infty}}{C_{w-C_{\infty}}}
\end{gathered}
$$$$
\text { L, } \delta, \varepsilon \text { and } \zeta \text { are the velocity, the therma }
$$
concentration and density slip factors respectively, and when $\mathrm{L}=\delta=\varepsilon=\zeta=0$, the no-slip condition is recovered, $l$ reference length of a sheet. The above boundary condition is valid when $\mathrm{x}<<l$ which occurs very near to the slit. We introduce the following similarity functions: 
Where $\psi$ is the stream function, the continuity equation is satisfied

$$
\mathrm{u}=\frac{\partial \psi}{\partial y}, \mathrm{v}=-\frac{\partial \psi}{\partial x}
$$

The radiative heat flux in the $\mathrm{x}$-direction is considered negligible as compared to $y$-direction. The radiative heat flux $\mathrm{q}_{\mathrm{r}}$ is given by

$$
q_{r}=-4 \frac{\sigma}{3 K^{*}} \frac{\partial T^{4}}{\partial y^{4}}
$$

Where $\sigma^{*}$ and $\mathrm{K}^{*}$ are the Stefan-Boltzmann constant and the mean absorption coefficient, respectively. We assume that the temperature difference within the flow is sufficiently small such that the term $\mathrm{T}^{4}$ may be expressed as a linear function of temperature. This is done by expanding $T^{4}$ in a Taylor series about a free stream temperature $T_{\infty}$ as follows:

$$
\mathrm{T}=T_{\infty}^{4}+4 T_{\infty}^{3}\left(\mathrm{~T}-T_{\infty}^{4}\right)+6 T_{\infty}^{2}\left(\mathrm{~T}-T_{\infty}^{4}\right)^{2}+\ldots
$$

If we neglect higher-order terms in the above Eq. (13) beyond the first order in

( $\left.\mathrm{T}-T_{\infty}\right)$, we have:

$$
\mathrm{T}^{4} \cong 4 T_{\infty}^{3}-3 T_{\infty}^{4}
$$

Thus, substituting Eq. (14) into Eq. (12), we have:

$$
q_{r}=-\frac{16 T_{\infty}^{3} \sigma^{*}}{3 K^{*}} \frac{\partial T}{\partial y}
$$

Using the boundary layer approximations with the similarity functions, the transformed governing equations and boundary conditions are then obtained as:

$$
f^{\prime \prime \prime}+f f^{\prime \prime}-\left(f^{\prime 2}\right)-\mathrm{M} f^{\prime}=0
$$

Where the primes denote differentiation with respect to $\eta$ and the parameter appearing in eqs. (16-19) are defined as:

$$
\begin{gathered}
\operatorname{Pr}=\frac{v}{\alpha}, L e=\frac{v}{D_{b}}, L b=\frac{v}{D_{m}} \mathrm{Pe}=\frac{b w_{c}}{D_{m}}, \Omega=\frac{n_{\infty}}{n_{w-n_{\infty}}}, N_{b}=\frac{\tau\left(C_{w-} C_{\infty}\right) D_{b}}{\mathrm{v}}, \\
N_{t}=\frac{\tau\left(T_{w-} T_{\infty}\right) D_{t}}{\mathrm{v} T_{\infty}}, E c=\frac{\left(u_{w}\right)^{2}}{c_{p}\left(T_{w}-T_{\infty}\right)}, \mathrm{R}=\frac{4 T_{\infty}^{3} \sigma^{*}}{3 K^{*} K}, \mathrm{M}=\frac{\sigma B_{o}^{2}}{\rho a}, \xi=L \sqrt{\frac{a}{v}}, \beta=\delta \sqrt{\frac{a}{v}} \\
\gamma=\varepsilon \sqrt{\frac{a}{v}}, \varphi=\zeta \sqrt{\frac{a}{v}}
\end{gathered}
$$

In Eqs. (16-20), Pr, Le, Lb, $\Omega, \mathrm{Nb}, \mathrm{Nt}, \mathrm{Pe}, \mathrm{Ec}, \mathrm{R}, \mathrm{M}, \xi$, $\beta, \gamma$ and $\varphi$ represent Prandtl number, Traditional Lewis number, Bioconvection Lewis number, Bioconvection concentration difference parameter, Brownian motion parameter, thermophoresis parameter, Bioconvection Péclet number, Eckert number, thermal radiation, Magnetic parameter, Velocity slip

$$
\mathrm{C}_{\mathrm{f}}=\frac{\tau_{w}}{\rho_{f} u_{0}^{2}}, \mathrm{Nu}_{\mathrm{x}}=\frac{q_{w} x}{k\left(T_{w}-T_{\infty}\right)}, \mathrm{Sh}_{\mathrm{x}}=\frac{q_{m} x}{D_{b}\left(T_{w}-T_{\infty}\right)}, \mathrm{Nn}_{\mathrm{x}}=\frac{x q_{n}}{D_{n}\left(n_{w}-n_{\infty}\right)}
$$

Where the heat flux $\mathrm{q}_{\mathrm{w}}$ and mass flux $\mathrm{h}_{\mathrm{m}}$ are given as:

$$
\mathrm{q}_{\mathrm{w}}=-\mathrm{k}\left(\frac{\partial T}{\partial y}\right) \mathrm{y}=0, \mathrm{~h}_{\mathrm{m}}=-\mathrm{D}_{\mathrm{b}}\left(\frac{\partial C}{\partial y}\right) \mathrm{y}=0
$$

Using Eqs. (21) and (22)

$$
\mathrm{C}_{\mathrm{fx}}=\left(R e_{x}\right)^{-\frac{1}{2}} \mathrm{C}_{\mathrm{f}}=-f^{\prime \prime}(0), N u_{x}=\left(R e_{x}\right)^{-\frac{1}{2}} \mathrm{Nu}=-\theta^{\prime}(0), S h_{x}=\left(R e_{x}\right)^{-\frac{1}{2}} \mathrm{Sh}=-\phi^{\prime}(0), N n_{x}=\left(R e_{x}\right)^{-\frac{1}{2}} \mathrm{Nn}=-\chi^{\prime}(0)
$$

\section{Numerical Solution}

The governing equations with the associated boundary conditions Eqs. (16)- (19) are numerically solved using fourth order Runge-Kutta method based shooting technique with Matlab package. Firstly, they were converted into first order linear differential equations using shooting technique and Runge-Kutta method to solve first order differential equations. We assumed the unspecified initial conditions for 
unknown variables, the transformed first order differential equations are integrated numerically as an initial valued problem until the given boundary conditions are satisfied.

Equations (16)-(19) are reduced to systems of first order differential equations

\section{Results and Discussion}

This section deals with graphical and numerical results of all the governing parameters arises in the governing flow problem. Eqs. (16-19) subject to the boundary conditions, Eqs. (20) and (21), were solved numerically using a fourthfifth order Runge-Kutta Fehlberg method to solve the boundary value problems numerically. The validity of this study is generally attested in tables $1-2$ to by its agreement with other generally accepted and published works in the same line of study. The present work's validity was tested by comparing it with the works of Wubshet and Bandari. [14] (MHD boundary layer flow and heat transfer of a nanofluid past a permeable strecting sheet with velocity and thermal slip), Andersson [15] (Slip flow past a stretching surface) and Hayat et al, [16] (MHD flow and heat transfer over permeable stretching sheet with slip conditions). The result from this research was found to be in excellent agreement with theirs comparison of Results for the skin friction $f^{\prime \prime}(0)$ and reduced Nusselt number $-\theta^{\prime}(0)$. Numerical values of local Nusselt number, skin friction coefficient, local Sherwood number and motile microorganism of local density are presented in Tables 3-4 against all the pertinent parameters.

Table 1. Comparison of skin friction coefficient - $f^{\prime \prime}(0)$ for different values of $\xi$ when $\lambda=\varphi=0$.

\begin{tabular}{llllll}
\hline $\boldsymbol{\xi}$ & $\mathbf{M}$ & $\begin{array}{l}\text { Anderson } \\
{[\mathbf{1 5}]}\end{array}$ & $\begin{array}{l}\text { Haya et al } \\
{[\mathbf{1 6 ]}}\end{array}$ & $\begin{array}{l}\text { Wubshet and } \\
\text { Bandari [14] }\end{array}$ & $\begin{array}{l}\text { Present } \\
\text { Result }\end{array}$ \\
\hline 10 & & 0.0812 & 0.081249 & & 0.0812 \\
0.0 & & 1.0000 & 1.0000 & & 0.9998 \\
& 0.0 & & & 1.2808 & 1.2799 \\
& 0.5 & & & 1.5000 & 1.5000 \\
& 1.0 & & 1.6861 & 1.6861 \\
& 1.5 & & & 1.8508 & 1.8508 \\
& 2.0 & & & 2.0000 & 2.0000 \\
\hline
\end{tabular}

Table 2. Comparison of local Nusselt number $-\theta^{\prime}(0)$ for different values of Le and Ntwhen $\lambda=M=R=0.5, \xi=\beta=\gamma=\varphi=1, \operatorname{Pr}=1, E c=N b=0.2$.

\begin{tabular}{llll}
\hline Le & Nt & Wubshet and Bandari [14] & Present Result \\
\hline 5 & 0.2 & 0.3980 & 0.3974 \\
10 & & 0.3993 & 0.3990 \\
15 & & 0.4001 & 0.3999 \\
20 & & 0.4005 & 0.4005 \\
& 0.1 & 0.3947 & 0.3943 \\
& 0.3 & 0.3915 & 0.3911 \\
& 0.4 & 0.3884 & 0.3880 \\
& 0.5 & 0.4002 & 0.4000 \\
\hline
\end{tabular}

Table 3. Computation showing the skin friction coefficient $-f^{\prime \prime}(0)$, local Nusselt $-\theta^{\prime}(0)$, local Sherwood number $-\emptyset^{\prime}(0)$ and local microorganisms density number - $\chi^{\prime}(0)$ when $M=1, R=0.5, P r=10, E c=N t=N b=P e=0.2, \Omega=L b=0.1$ for different values of $\xi, \beta, \gamma$ and $\varphi$.

\begin{tabular}{|c|c|c|c|c|c|c|c|}
\hline$\xi$ & $\beta$ & $\gamma$ & $\varphi$ & $-f^{\prime \prime}(0)$ & $-\boldsymbol{\theta}^{\prime}(\mathbf{0})$ & $-\phi 9(0)$ & $-\chi^{\prime \prime}(0)$ \\
\hline 0.0 & 0.5 & 0.5 & 0.5 & 1.6861 & 0.7595 & 1.1331 & 0.2186 \\
\hline 0.1 & & & & 1.4062 & 0.8370 & 1.0647 & 0.2384 \\
\hline 0.2 & & & & 1.2116 & 0.8835 & 1.0178 & 0.2498 \\
\hline 0.3 & & & & 1.0673 & 0.9337 & 0.9833 & 0.2568 \\
\hline \multirow[t]{8}{*}{0.5} & 0.0 & 0.5 & 0.5 & & 1.6539 & 0.7417 & 0.3414 \\
\hline & 0.2 & & & & 1.3027 & 0.8338 & 0.3073 \\
\hline & 0.4 & & & & 1.0467 & 0.9061 & 0.2773 \\
\hline & 0.6 & & 0.5 & & 0.8644 & 0.9997 & 0.2535 \\
\hline & & 0.0 & & & 0.7888 & 2.5663 & 0.1014 \\
\hline & & 0.1 & & & 0.8545 & 1.9016 & 0.1000 \\
\hline & & 0.2 & & & 0.8927 & 1.5108 & 0.0993 \\
\hline & & 0.3 & & & 0.9176 & 1.2534 & 0.0989 \\
\hline \multirow[t]{4}{*}{0.5} & 0.5 & 0.5 & 0.0 & & & & 0.3025 \\
\hline & & & 0.1 & & & & 0.2941 \\
\hline & & & 0.2 & & & & 0.2861 \\
\hline & & & 0.3 & & & & 0.2786 \\
\hline
\end{tabular}

Table 3 presents the variation of the skin friction coefficient, local Nusselt number, local Sherwood number and local microorganism density number in relation to different slip parameters. It is observed that as velocity slip increases both local Nusselt number and local microorganism density number increase while skin coefficient and local Sherwood number decrease. This concludes that increment in velocity slip leads to increase in rate of heat transfer as well as microorganism density but decrease in mass rate.

The effect of thermal slip parameter on the physical quantities, we observe that as temperature slip increase the rate of heat transfer and microorganism density are decreased.

The effects of nanoparticle concentration slip parameter also observed in table 3 . It was noticed that mass transfer rate and microorganism density decrease as nanoparticle concentration slip increases, but heat transfer rate increases. 
Table 3 also illustrated the effect of motile microorganism density slip parameter on various physical quantities. It was found that wall motile microorganisms flux decreased with higher motile microorganism density slip effect.

Table 4 presents the variation of the local microorganism density number - $\chi^{\prime \prime}(0)$ in relation to the bioconvection Lewis number $\mathrm{Lb}$, microorganism concentration $\Omega$ and bioconvectionPéclet number Pe. On observing this table, as the values $\mathrm{Lb}, \Omega$ and Pe increase, the local microorganism density number increase. Therefore for higher value of value $\mathrm{Lb}, \Omega$ and Pe the microorganism speed will be reduced and the diffusivity of the microorganisms will be reduced. This will leads to reduced microorganisms' density in the boundary layer and results in increase mass transfer rate.

Table 4. Computation showing the local microorganisms density number $\chi^{\prime \prime}(0)$ when $M=1, R=0.5, \xi=\beta=\gamma=\alpha_{1}=0.5,=P e=0.2, N t=N b=E c=$ 0.2 for different values of $\mathrm{Ec}, \mathrm{Nt}, \mathrm{Nb}$ and $\mathrm{Pr}=10$.

\begin{tabular}{llll}
\hline $\mathbf{L b}$ & $\mathbf{P e}$ & $\mathbf{\Omega}$ & $-\boldsymbol{\chi}^{\prime \prime}(\mathbf{0})$ \\
\hline 0.1 & 0.2 & 0.2 & 0.2646 \\
0.2 & & & 0.3105 \\
0.3 & & 0.3584 \\
0.4 & & 0.4053 \\
& 0.1 & & 0.1924 \\
& 0.2 & & 0.2646 \\
& 0.3 & & 0.3313 \\
& 0.4 & & 0.3931 \\
& & 0.0 & 0.2502 \\
& & 0.05 & 0.2574 \\
& & 0.1 & 0.2646 \\
& & 0.15 & 0.2718 \\
& & 0.2 & 0.2790 \\
\hline
\end{tabular}

Table 5. Computation showing the local Nusselt $-\theta^{\prime}(0)$, local Sherwood number $-\phi^{\prime}(0)$ and local microorganisms density number $-\chi^{\prime}(0)$ when $\xi=$ $\beta=\gamma=\varphi=0.5, P r=10, E c=N t=N b=P e=0.2, \Omega=L b=0.1$ for different values of Le, $M$ and $R$.

\begin{tabular}{llllll}
\hline $\mathbf{L e}$ & $\mathbf{M}$ & $\mathbf{R}$ & $-\boldsymbol{\theta}^{\prime}(\mathbf{0})$ & $-\boldsymbol{\phi} 9(\mathbf{0})$ & $-\boldsymbol{\chi}^{\prime \prime}(\mathbf{0})$ \\
\hline 4.0 & 1.0 & 0.5 & 0.9510 & 0.7987 & 0.2662 \\
6.0 & & & 0.9479 & 1.0408 & 0.2637 \\
8.0 & & 0.9518 & 1.1962 & 0.2628 \\
10 & & 0.9575 & 1.3059 & 0.2626 \\
12 & & & 0.9636 & 1.3880 & 0.2627 \\
5.0 & 0.0 & & 1.0297 & 0.9420 & 0.2874 \\
& 0.5 & & 0.9813 & 0.9393 & 0.2735 \\
& 1.0 & & 0.9480 & 0.9350 & 0.2646 \\
& 1.5 & & 0.9232 & 0.9302 & 0.2583 \\
& 2.0 & & 0.9038 & 0.9255 & 0.2536 \\
& 1.0 & 0.0 & 1.0627 & 0.8981 & 0.2815 \\
& & 0.1 & 1.0362 & 0.9064 & 0.2778 \\
& & 0.2 & 1.0117 & 0.9142 & 0.2743 \\
& & 0.3 & 0.9890 & 0.9216 & 0.2709 \\
& & 0.4 & 0.9678 & 0.9285 & 0.2677 \\
\hline
\end{tabular}

Table 5 presents the variation of the local Nusselt number, local Sherwood number and local microorganism density number in relation to magnetic field, Lewis number and thermal radiation. On observing this table, as the values of Lewis number increase, the values of local Nusselt number and local Sherwood number increase, but opposite effect is observed in local microorganism density number. In addition, as the values of magnetic field parameters increase, both the values of the local Nusselt number, local Sherwood number and local microorganism density number decrease. However, increase in the thermal radiation increases local Sherwood number but reduces rate of heat transfer and local microorganism density number.

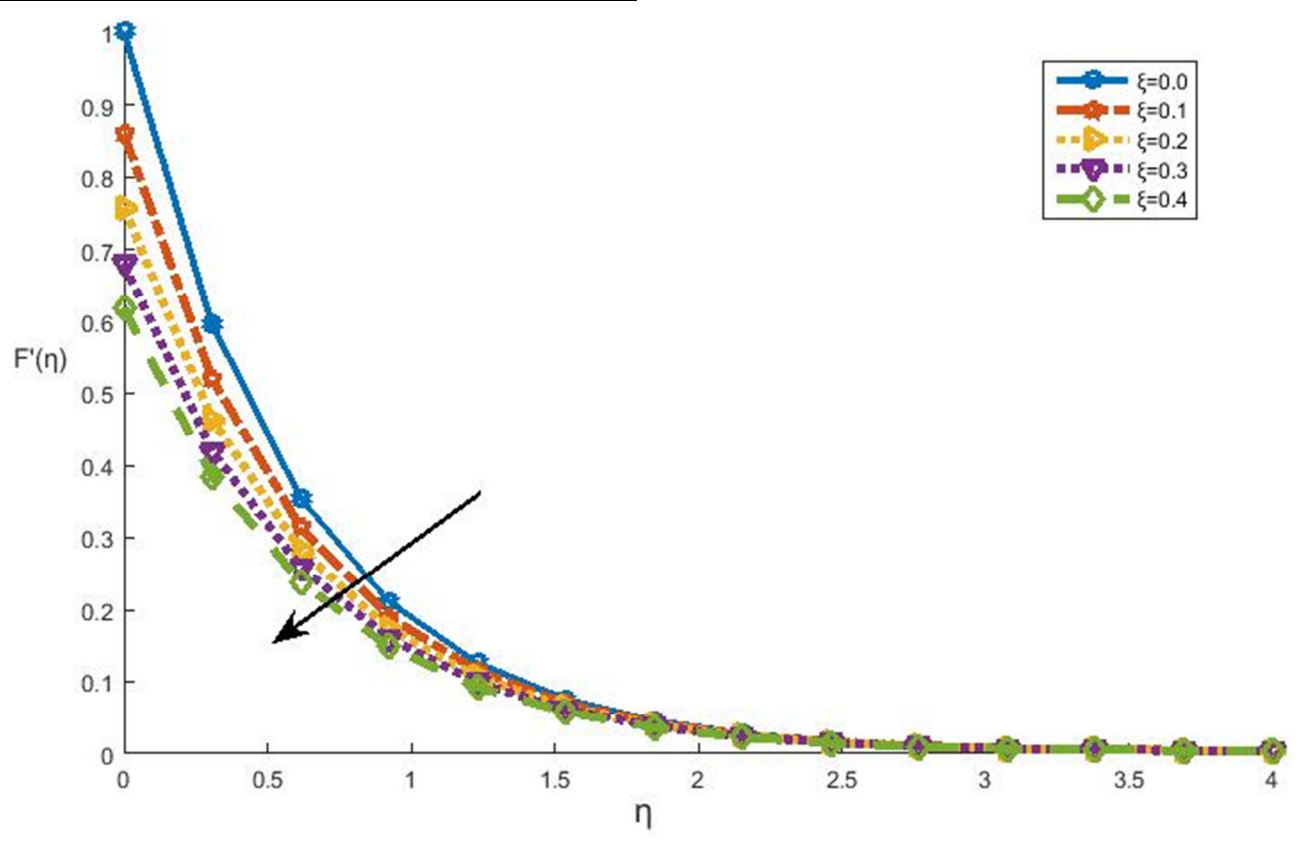

Figure 1. Effect of velocity slip parameter $\xi$ on velocity distribution when $m=0$. 


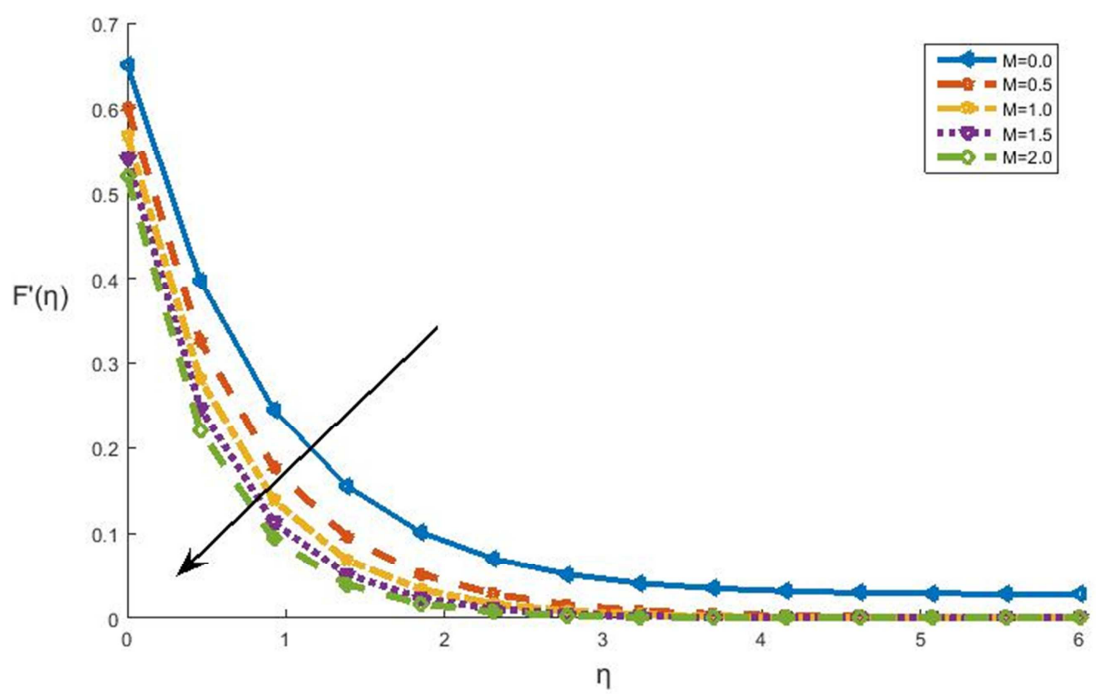

Figure 2. Effect magnetic field parameter $M$ on velocity distribution when $R=0.5, N t=N b=E c=0.2, R=0.5, L b=\Omega=0.1, \quad M=1, \varphi=\beta==0.5, L e=5$, $P e=0.2 P e=0.2$ and $P r=10$.

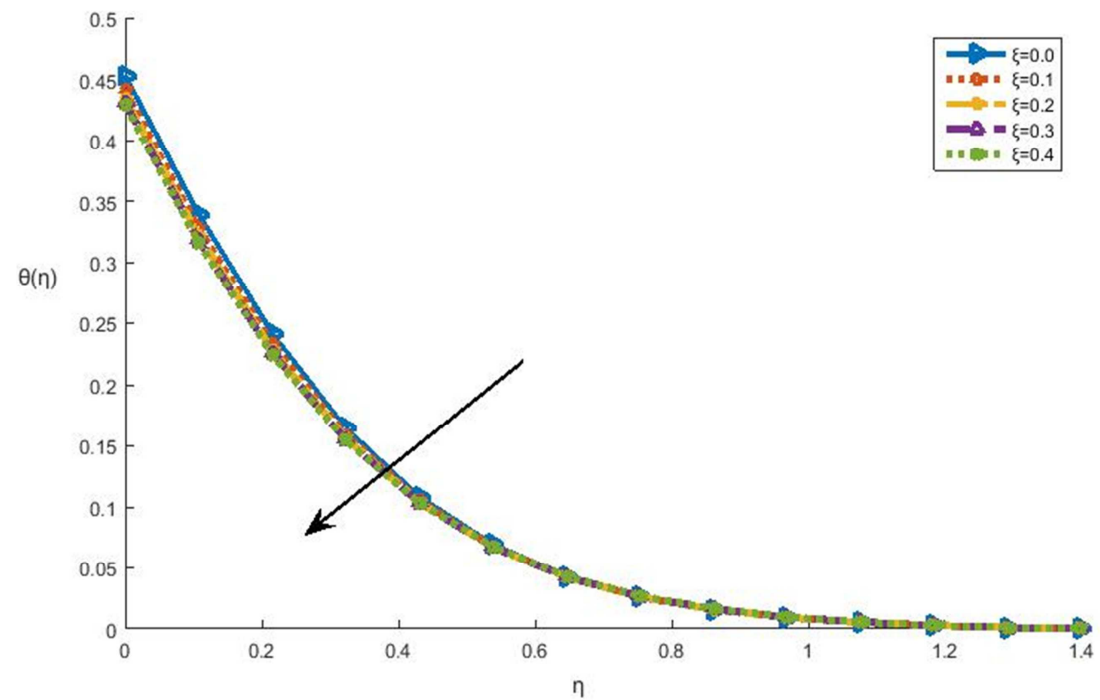

Figure 3. Effect of velocity slip parameter $\xi$ on temperature distributionwhen $N t=N b=E c=0.2, R=0.5, L b=\Omega=0.1, M=1, \varphi=\beta==0.5, L e=5, P e=0.2$ and $\operatorname{Pr}=10$.

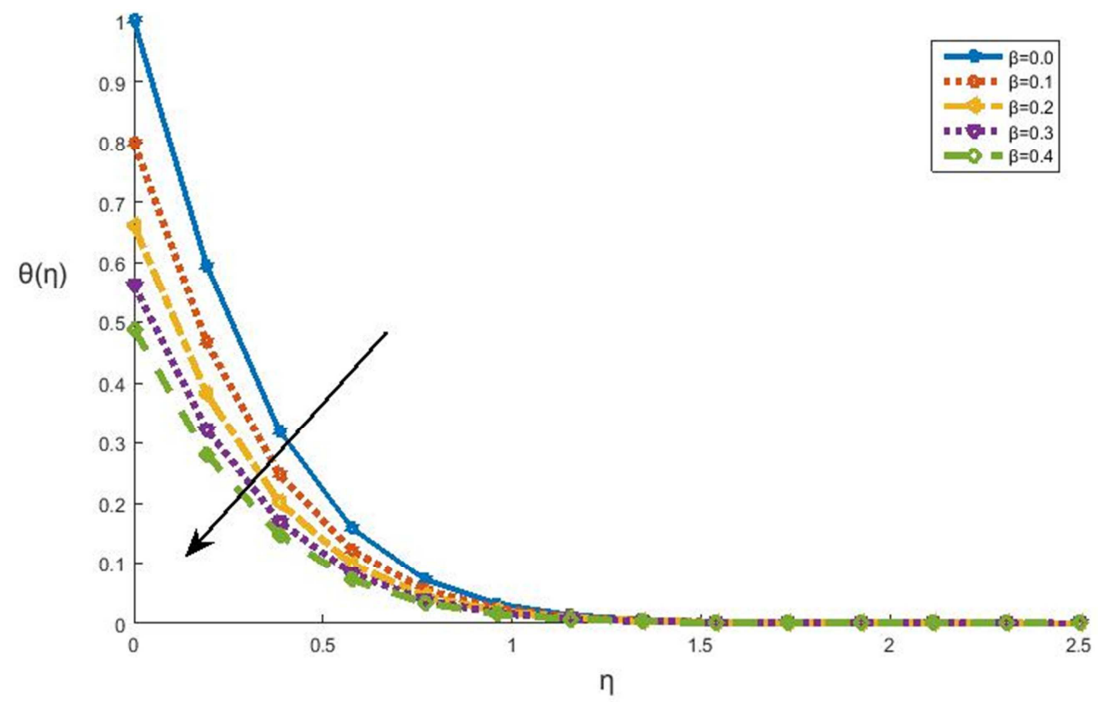

Figure 4. Effect of temperature slip $\beta$ on temperature distribution when $N t=N b=E c=0.2, R=0.5, L b=\Omega=0.1, M=1, \xi=\varphi=\gamma=05, L e=5, P e=0.2$ and $P r=10$. 


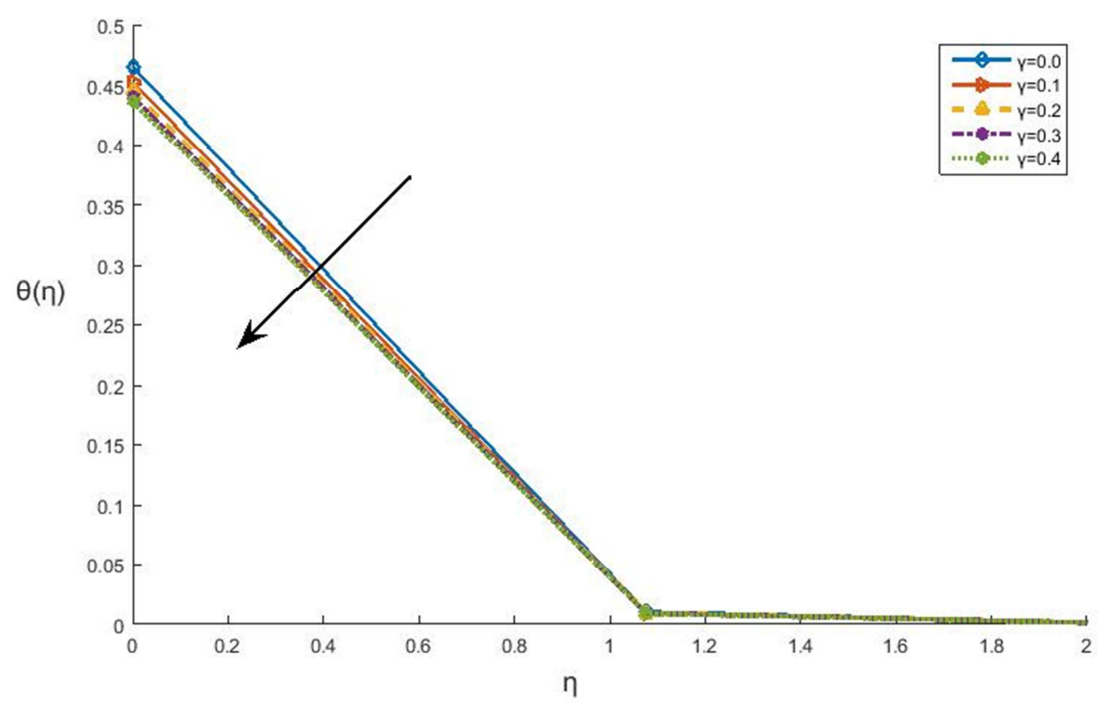

Figure 5. Effect of nanoparticle concentration slip parameter $\gamma$ on temperature distribution when $N t=N b=E c=0.2, R=0.5, L b=\Omega=0.1, M=1, \xi=\beta=\varphi=0.5$, $L e=5, P e=0.2$ and $P r=10$.

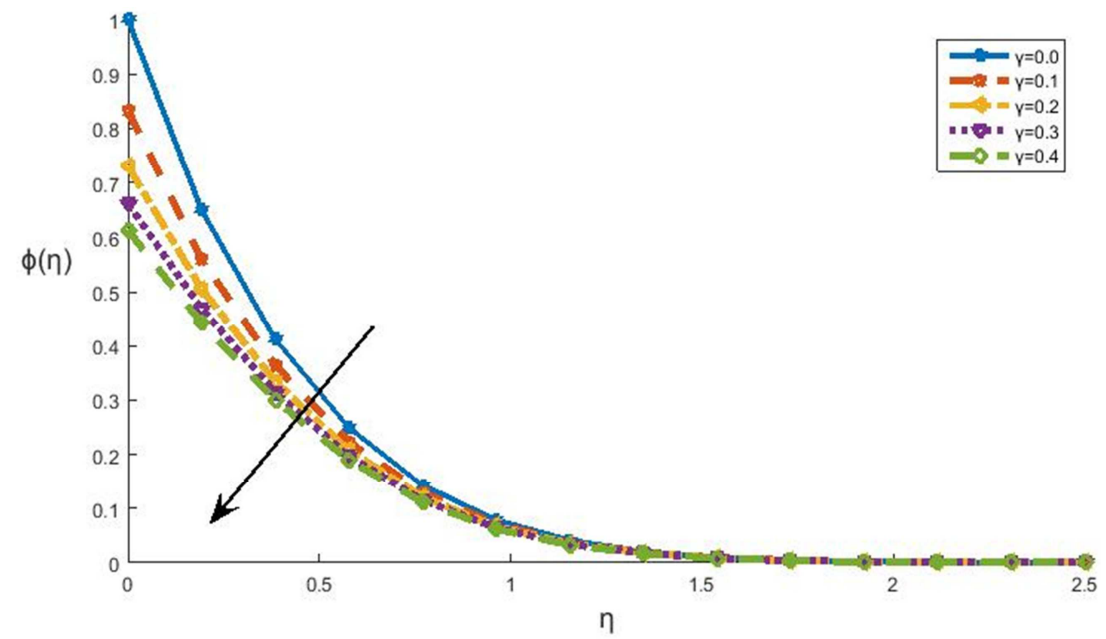

Figure 6. Effect of nanoparticle concentration slip yon nanoparticle concentration distribution when $N t=N b=E c=0.2, R=0.5, L b=\Omega=0.1, M=1, \xi=\beta=\varphi=0.5$, $L e=5, P e=0.2$ and $P r=1$.

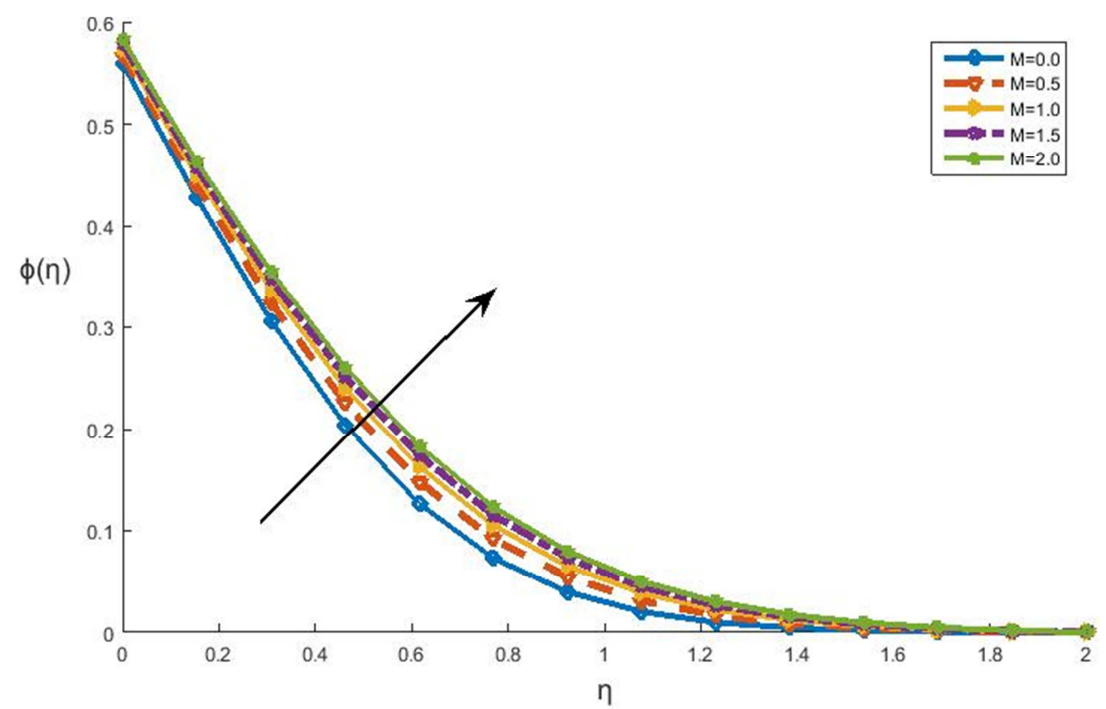

Figure 7. Effect of magnetic field $M$ on nanoparticle concentration distribution when $N t=N b=E c=0.2, R=0.5, L b=\Omega=0.1, \xi=\beta=\gamma=\varphi=0.5, P e=0.2$ and $\operatorname{Pr}=10$. 


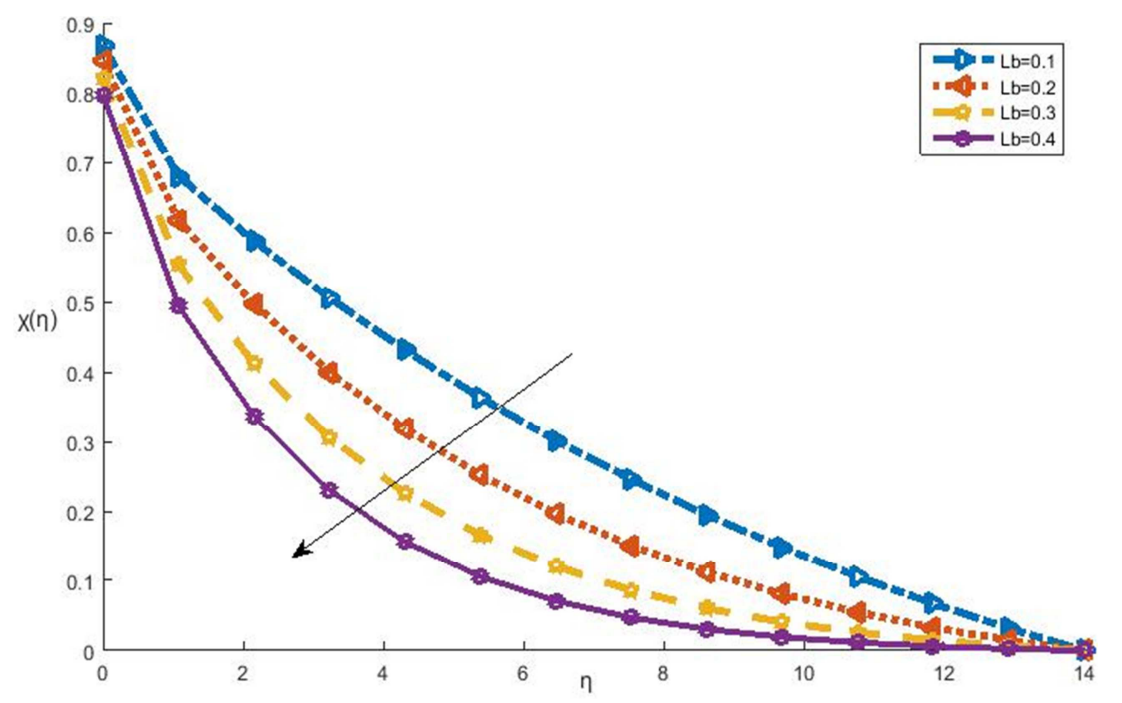

Figure 8. Effect of bioconvection Lewis number Lb on motile microorganism density distribution when $N t=N b=E c=0.2, R=0.5, L b=\Omega=0.1, M=1, \xi=\beta=\varphi=\gamma$ $=0.5, P e=0.2, L e=5$ and $P r=10$.

$x(\eta)$
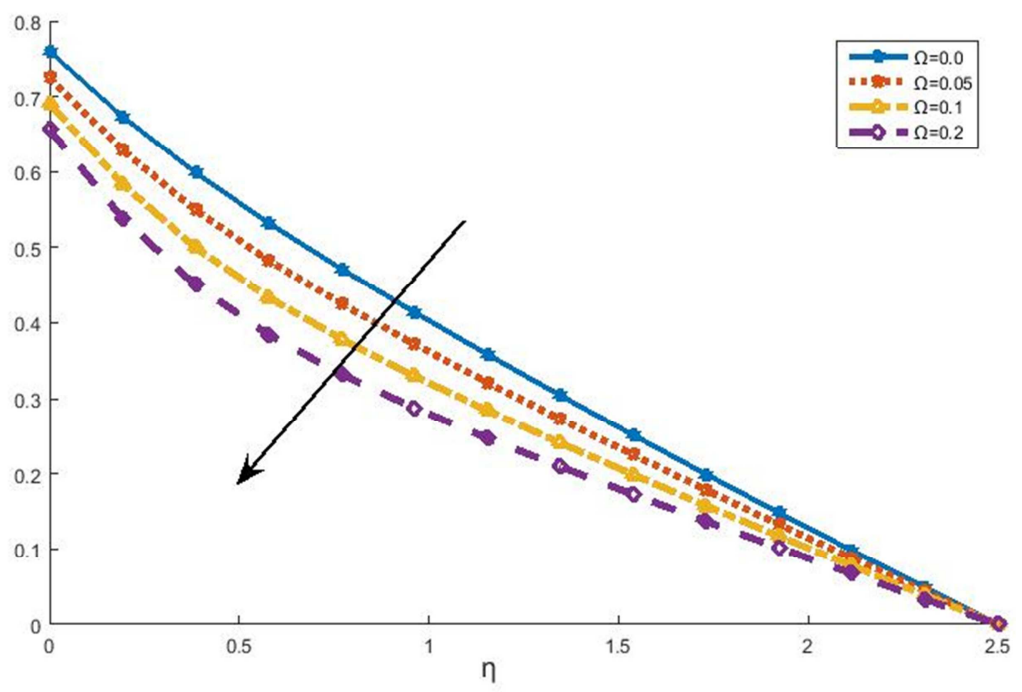

Figure 9. Effect of microorganism concentration $\Omega$ on motile microorganism density distribution when $N t=N b=E c=0.2, R=0.5, L b=\Omega=0.1, M=1, \xi=\beta=\varphi=\gamma$ $=0.5, P e=0.2, L e=5$ and $P r=10$.

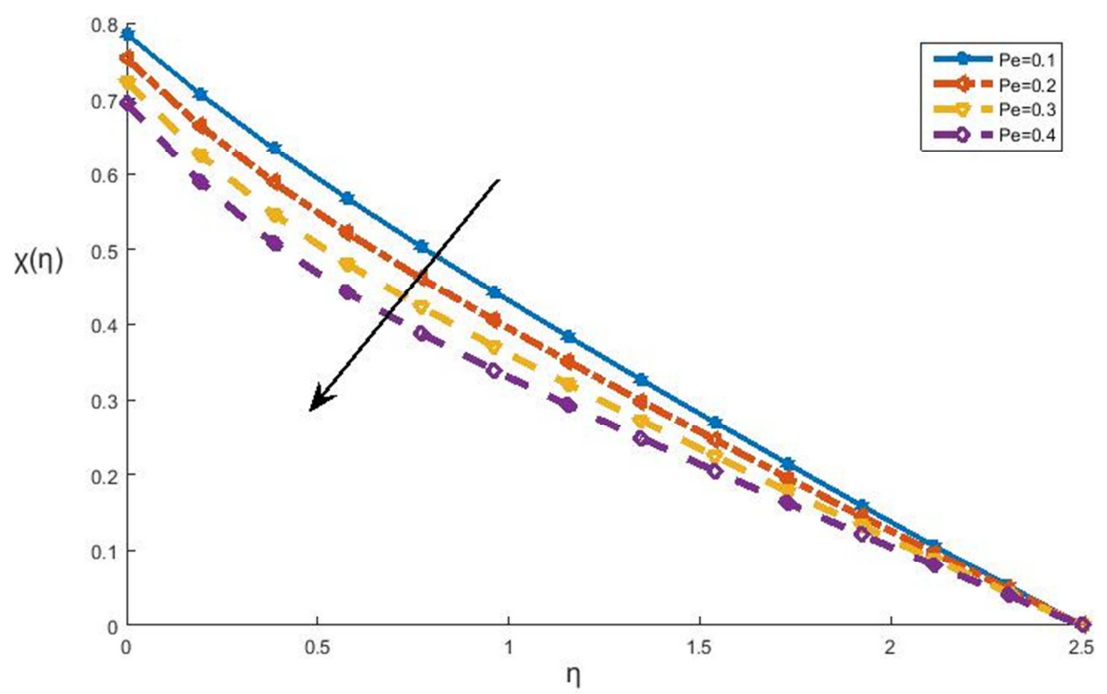

Figure 10. Effect of bioconvectionpécletPe on motile microorganism density distribution when $N t=N b=E c=0.2, R=0.5, L b=\Omega=0.1, M=1, \xi=\beta=\varphi=\gamma=0.5$, $L e=5$ andPr $=10$. 


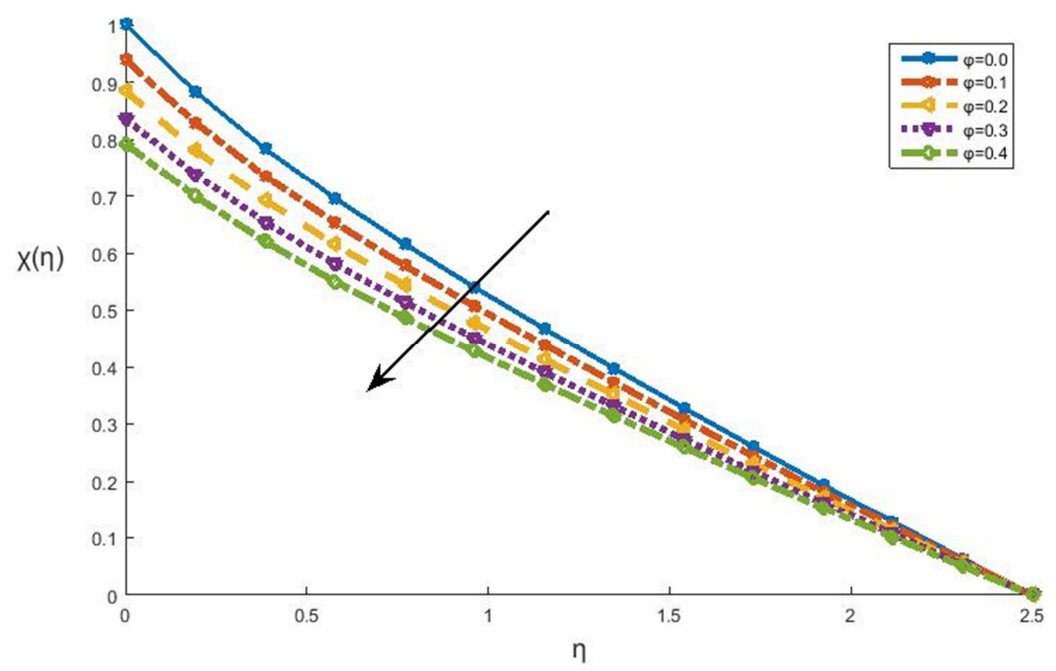

Figure 11. Effect of microorganism density slip $\varphi$ on motile microorganism density distribution when $N t=N b=E c=0.2, R=0.5, L b=\Omega=0.1, M=1, \xi=\beta=\varphi=\gamma$ $=0.5, P e=0.2, L e=5$ and $P r=10$.

Figures1-2 Showed the effect of velocity slip and magnetic field parameters on velocity distribution. It is revealed that the velocity of fluid decreases with increase in both velocity slip parameter $\xi$ and magnetic parameter $\mathrm{M}$. The reason for this phenomenon is that application of magnetic field to an electrically conducting nanofuid gives rise to a resistive force which opposes the fluid motion.

Figures 3-5 Show the effects of various parameters on the temperature distribution. We noticed that the temperature of the flow is continuously decreasing as the value of $\xi, \beta$ and $\gamma$ increase. When the thermalslip parameter increases, the movement of the fluid within the boundary layer will not be very sensitive due to the heating influence of the sheet surface and leads to decrease in thermal boundary layer.

The influences of $\gamma$ and $\mathrm{M}$ parameters on nanoparticle concentration of the fluid are demonstrated in figures6-7. For several increase values of nanoparticleconcentration slip parameter $\gamma$, the nanoparticle volume fraction decreases. Opposite effect is observed for magnetic field parameter M, as the value of $\mathrm{M}$ increases, the nanoparticle concentration increases and enhancing Lorentz force which retards cause the nanofluid flow and Nusselt number reduces.

We investigated the bioconvection in nanofluid flow over a stretching sheet surface with microorganism. The effect of slip parameters on the microorganism concentration of the fluid and other pertinent parameters are shown in Figures 811. We noticed that increase in bioconvection Lewis number $\mathrm{Lb}$, microorganism concentration $\Omega$ and bioconvectionPéclet number $\mathrm{Pe}$ and slip parameter $\varphi$ lead to decrease in microorganism density in the boundary layer. The wall motile microorganisms flux decreased with higher motile microorganism density slip, $\mathrm{Pe}, \mathrm{Lb}$ and $\Omega$ effects

\section{Conclusion}

In this study, the effect of the slip parameters on bioconvection Lewis number $\mathrm{Lb}$, microorganism concentration, $\Omega$ and bioconvectionPéclet number, $\mathrm{Pe}$ is investigated. The main findings of the study show that velocity profiles decrease with the magnetic field and velocity slip parameter while temperature profile decreases with increase in the temperature slip, velocity slip and nanoparticle concentration slip parameter. The skin friction coefficient decreases as the values of velocity slip parameter increases.

It was also found that nanoparticle concentration profile decreases with increase in the nanoparticle concentration slip but increases with magnetic field parameter. Nusselt number increases with an increase in velocity slip and nanoparticle concentration slip parameter whereas the Sherwood number decreases. Finally, the local microorganism transfer rate is increased with greater values of bioconvection Lewis number $\mathrm{Lb}$, microorganism concentration $\Omega$ and bioconvection Péclet number Pe.

\section{Appendix}

\section{Nomenclature}

$\xi \quad$ Velocity slip parameter

$\beta \quad$ thermal slip parameter

$\gamma \quad$ concentration slip parameter

$\chi \quad$ dimensionless number density of motile

$\chi \quad$ microorganism

$\varphi \quad$ microorganism density slip parameter

$\mathrm{C}_{\mathrm{f}} \quad$ skin friction coefficient

$\mathrm{D}_{\mathrm{b}} \quad$ Brownian diffusion coefficient

$D_{t} \quad$ thermophoresis diffusion coefficient

f dimensionless stream function

$\mathrm{K}$ thermal conductivity

Le Lewis number

$\mathrm{Lb}$ bioconvention Lewis number

$\mathrm{Pe} \quad$ bioconventionpéclet number

$\Omega \quad$ bioconvention concentration difference

M magnetic parameter

$\mathrm{Nb}$ Brownian motion parameter

$\mathrm{Nt}$ thermophoresis parameter

$\mathrm{Nu}_{\mathrm{x}} \quad$ local Nusselt number 
$\mathrm{Nn}_{\mathrm{x}} \quad$ local motile microorganism density

Pr Prandtl number

$\mathrm{R} \quad$ thermal radiation parameter

$\mathrm{Re}_{\mathrm{x}} \quad$ local Reynolds number

$\mathrm{T}$ temperature of the fluid inside the boundary layer

$\mathrm{Sh}_{\mathrm{x}} \quad$ local Sherwood number

$\mathrm{T}_{\mathrm{w}} \quad$ uniform temperature over the surface of the sheet

$\mathrm{T}_{\infty} \quad$ ambient temperature

$\mathrm{C}_{\mathrm{w}} \quad$ concentration

$\mathrm{C}_{\infty} \quad$ ambient concentration

$\mathrm{C}$ nanoparticles concentration fraction

$\mathrm{u}, \mathrm{v} \quad$ velocity component along $\mathrm{x}$ - and $\mathrm{y}$-direction

$\mathrm{u}_{\mathrm{x}} \quad$ stretching velocity of the sheet

$\mathrm{B}_{0} \quad$ magnetic field strength

$\sigma^{*} \quad$ Stefan-Boltzmann constant

$\mathrm{K}^{*} \quad$ absorption coefficient

\section{Greek Symbols}

$\eta \quad$ dimensionless similarity variable

$\mu \quad$ dynamic viscosity of the fluid

$\sigma \quad$ electrical conductivity

$v \quad$ kinematic viscosity of the fluid

$\phi \quad$ dimensionless concentration function

$\rho_{\mathrm{f}} \quad$ density of the fluid

$(\mathrm{c} \rho)_{\mathrm{f}} \quad$ heat capacity of the fluid

(c $\rho) \mathrm{p}$ effective heat capacity of a nanoparticle

$\psi \quad$ stream function

$\alpha \quad$ thermal diffusivity

$\theta \quad$ dimensionless temperature

$\tau \quad$ parameter defined by $\frac{(\mathrm{c} \rho) \mathrm{f}}{(\mathrm{c} \rho) \mathrm{p}}$

\section{Subscripts}

$\infty \quad$ Condition at the free stream

$w \quad$ Condition at the surface

\section{References}

[1] Choi, S. U. S., Developments and Applications of NonNewtonian Flows, ASME Press, NewYork, USA, 1995.

[2] J. Buongiorno, W. Hu, Nanofluid coolants for advanced nuclear power plants. Paper No. 5705, Proceedings ofICAPP '05, Seoul, May 15-19, 2005.

[3] J. Buongiorno, Convective transport in nanofluids, ASME J. Heat Transf. 128 (2006) 240-250.

[4] W. Duangthongsuk, S. Wongwises, Effect of thermophysical properties models on thepredicting of the convective heat transfer coefficient for low concentration nanofluid, Int. Commun. Heat Mass Transf. 35 (10) (December 2008) 1320-1326.

[5] A. V. Kuznetsov, D. A. Nield, Natural convective boundarylayer flow of a nanofluidpast a vertical plate, Int. J. Therm. Sci. 49 (2) (February 2010) 243-247.

[6] Rana, P. and Bhargava, R. Flow and heat transfer over a nonlinearly stretching sheet: Anumerical study. Comm. Nonl. Sci. and Numer. Simulat. 17, 212-226 (2012).
[7] Makinde OD, Aziz A. Boundary layer flow of a nanofluid past a stretching sheetwithconvective boundary condition. Int $J$ ThermSci 2011; 50: 1326-32.

[8] J. A. V. Kuznetsov, Thermo-bioconvection in a suspension of oxytactic bacteria, Int. Commun. Heat Mass Transfer32 (2005) 991-999.

[9] O. D. Makinde, W. A. Khan, Z. H. Khan, Buoyancy effects on MHD stagnation point flowandheat transfer of a nanofluid past a convectively heated stretching/shrinking sheet, Int. J. Heat Mass Transf. 62 (July 2013) 526-533.

[10] H. Xu and I. Pop, "Mixed convection flow of a nanofluid over a stretching surface with uniform free stream in; he presence of both nanoparticles and gyrotacticmicroorganisms," Int. J. Heat and Mass Transf75, 610-623 (2014).

[11] W. A. Khan and I. Pop, "Boundary-layer flow of a nanofluid past a stretching sheet," Int. J. Heat Mass transf. 53 (11-12), 2477-2483 (2010).

[12] Buongiorno, Convective transport in nanofluids, ASME J. Heat Transf. 128 (2006) 240-250.

[13] A. V. Kuznetsov, The onset of nanofluidbioconvection in a suspension containing bothnanoparticles and gyrotactic microorganisms, Int. Commun. Heat Mass Transf. 37 (10) (December 2010) 1421-1425.

[14] W. Ibrahim, B. Shanker, MHD boundary layer flow and heat transfer of a nanofluid past a permeable stretching sheet with velocity, thermal and solutal slipboundaryconditions. Int $J$ Heat Mass Transfer 2013; 75: 1-10.

[15] Andersson H. Slip flow past a stretching surface. ActaMech 2002; 158: 121-5.

[16] Hayat T, Qasim M, Mesloub S. MHD flow and heat transfer over permeable stretching sheetwith slip conditions. Int $J$ Numer Meth Fluid 2011; 66: 963-75.

[17] Sakiadis BC. Boundary layer behavior on continuous solid surface: II. The boundary layer on a continuous flat surface. J Am Ins ChemEng 1961; 7 (2): 221-5.

[18] R. Nazar, N. Amin, I. Pop, Unsteady boundary layer flow due to a stretching surfacein a rotatingfluid, Mech. Res. Commun. 31 (1) (2004) 121-128.

[19] Abel M. S,. Kumar K. A, Ravikumara R, MHD flow, and heat transfer with effects of buoyancy, viscous and Joules dissipation over a nonlinear vertical stretching porous sheetwith partial slip, Engineering 3 (3) (March 2011) 285291.

[20] A. Y. Bakier, Thermophoresis effects on heat and mass transfer in MHD flow over averticalstretching surface with radiation, Int. J. Fluid Mech. 36 (2010) 489-501.

[21] Wang CY. Stagnation slip flow and heat transfer on a moving plate. ChemEngSci 2006; 61: 7668-72.

[22] Fang T, Zhang J, Yao S. Slip MHD viscous flow over a stretching sheet - an exactsolution. Commun Non-linear SciNumerSimul 2009; 14: 3731-7.

[23] Aziz A. Hydrodynamic and thermal slip flow boundary layer over a flat platewith constant heat flux boundary condition. Commun Non-linear SciNumerSimul 2010; 15: 573-80. 